\title{
Téoros
}

Revue de recherche en tourisme

\section{Le Bas-Saint-Laurent et la Gaspésie se concertent pour conquérir les marchés internationaux}

\section{René Trépanier}

Volume 13, numéro 1, mars 1994

Bas-Saint-Laurent, Gaspésie, Iles-de-la-Madeleine : fascinantes

périphéries

URI : https://id.erudit.org/iderudit/1077771ar

DOI : https://doi.org/10.7202/1077771ar

Aller au sommaire du numéro

Éditeur(s)

Université du Québec à Montréal

ISSN

0712-8657 (imprimé)

1923-2705 (numérique)

Découvrir la revue

Citer cet article

Trépanier, R. (1994). Le Bas-Saint-Laurent et la Gaspésie se concertent pour conquérir les marchés internationaux. Téoros, 13(1), 22-23.

https://doi.org/10.7202/1077771ar d'utilisation que vous pouvez consulter en ligne. 


\section{Le Bas-Saint-Laurent et la Gaspésie se concertent pour conquérir les marchés internationaux}

René Trépanier"

Depuis bientôt cinq ans, deux associations touristiques régionales travaillent ensemble à commercialiser leur destination auprès des marchés internationaux. Pour ce faire, elles ont créé une nouvelle structure gérée par un comité inter-régional qui oeuvre sous le nom de Tourisme BasSaint-Laurent/Gaspésie. Cet exercice de concertation, un précédent au Québec, leur a permis de s'intégrer rapidement au réseau de distribution des voyages d'agrément et d'obtenir des résultats éloquents.

\section{L'implication du milieu}

La concertation inter-régionale constitue à la fois la plus grande force et le plus grand défidu Plan de commercialisation de Tourisme Bas-Saint-Laurent/Gaspésie. Tout a commencé en 1989. Sur le territoire, les promoteurs multiplient les rencontres d'information auprès des intervenants et des intervenantes touristiques. Il fautidentifier les produits exportables, définir les critères d'adhésion et convaincre des gestionnaires de souscrire au Plan de commercialisation. L'objectif ultime poursuivi par le Comité consiste à étaler la saison touristique en augmentant la clientèle internationale. Le milieu réagit en s'impliquant financièrement. Dès la première campagne de recrutement, 56 intervenants, dont une quinzaine d'hôteliers, des attractions, des transporteurs, des excursionnistes adhèrent à une stratégie qui promet des résultatsà moyen terme, en plus d'exiger une contribution financière annuelle pouvant atteindre $3750 \mathrm{~S}$. La campagne de 1991 permet de recruter un total de 77 membres et consolide l'appui du milieu qui, jusqu'a maintenant, a injecté près de $400000 \$$ dans le Plan de commercialisation.

\section{Les partenaires}

En moyenne, l'enveloppe budgétaire annuelle de Tourisme Bas-Saint-Laurent'

Monsieur René Trépanier est directeur des relations publiques pour Tourisme Bas-Saint-Laurent/ Gaspesie.

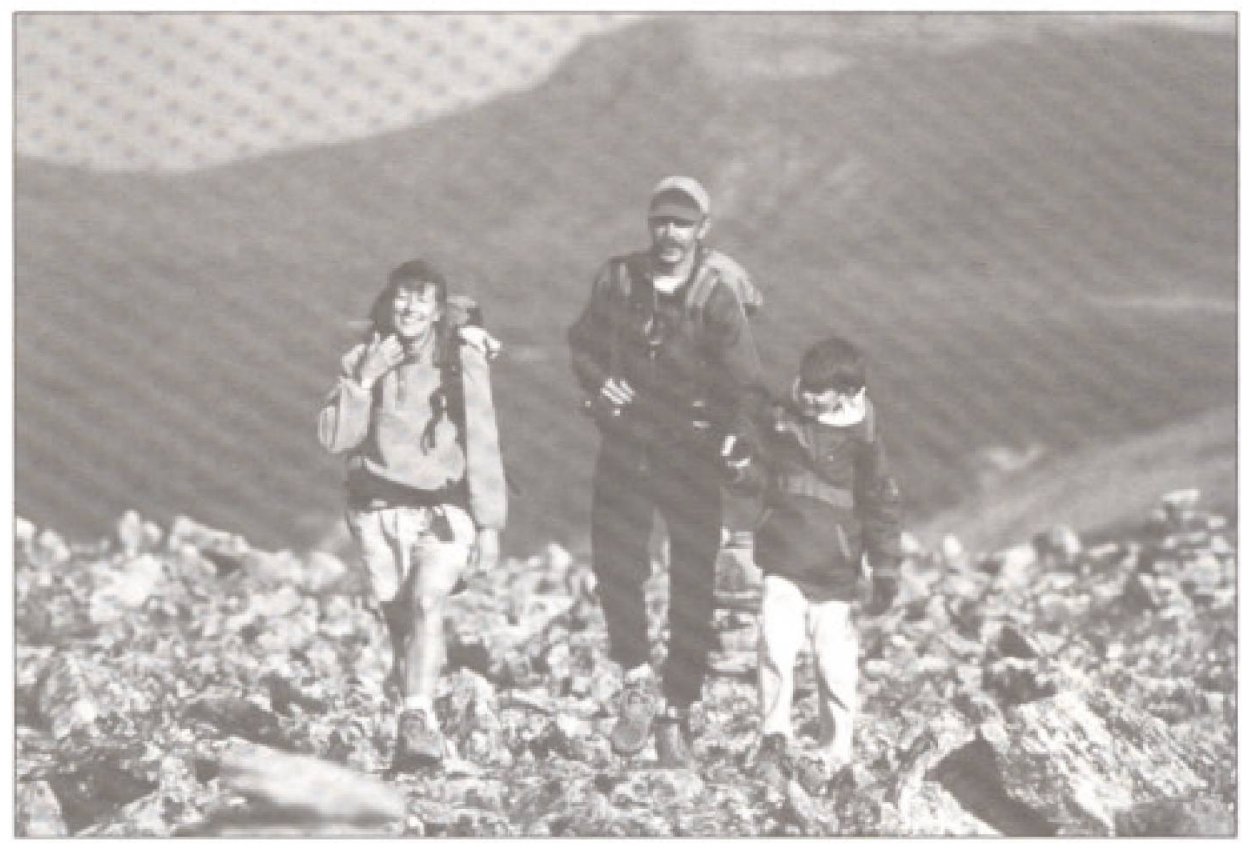

Randonnéte pédestre dans le Pare de la Gaspésie : =Une mer de montagnes so qui semblent dresser un mur infranchissable, végétation similaire à celle qui prévaut dans le Grand-Nord québx́cois, unique endroit au Québec où on reurouve le caribou des bois, lorignal et le cerf de Virginie dans le même territoire. On peut y pratiquer de nombreuses activités et on y retrouve un relais gastronomique, le Gíte du Mont-Albert.

Gaspésie atteint 225000 \$. Le Bureau fédéral de développement régional constitue son principal partenaire financier avec des investissements de $800000 \$$ depuis 1988. Par son programme de promotion coopératif, le ministère du Tourisme a, quant à lui, amené une contribution de 90 000 S. La firmeZins, Beauchesneetassociếs fût associée au projet pour la planification de la stratégie et l'élaboration d'un programme promotionnel. Le Comité de Tourisme Bas-Saint-Laurent/Gaspésieest composé des gens de l'industrie provenant des instances gouvernementales et du milieu. Deux permanents assurent les opérations.

\section{La stratégie}

La stratégie du Plan de commercialisation viseune meilleure pénétration du réseau de distribution des voyages d'agrément. En conséquence, les actions promotionnelles ont surtout été dirigées vers les intermé- diaires du monde du voyage, c'est-à-dire les voyagistes, les détaillants et les journalistes. Depuis le début de l'opération, les calendriers de représentation notent une participation à plus de quarante événements touristiques majeurs. Au moins 750 voyagistes et 200 journalistes de la presse touristique ont été rencontrés et figurent désormais dans le répertoire des contacts de Tourisme Bas-Saint-Laurent/Gaspésie.

Les interventions de Tourisme Bas-SaintLaurent/Gaspésie traduisent les efforts investis pour la recherche d'approches distinctives. Depuis son existence, l'organisme a rejoint ses cibles en présentant un nouveau genre de manuel de vente et en développant des concepts d'animation originaux. Ce fût le cas, en 1991, à Paris. Après un copieux repas de homards gaspésiens, près de 175 voyagistes et journalistes français et françaises ont misé, à coups de millions de Gaspé-dollars, sur les attraits de la région. Le commissairepriseur a fait monter les enchères et la 
frénésie. L'auditoire a apprécié. Tourisme Bas-Saint-Laurent/Gaspésie en a redonné, chaque année: ciné-conférence, quizz animé, soirées de contes et de chansons.

Unevingtaine detournéesdefamiliarisation ontégalementétéorganisées par leComité qui croit aux retombées de cette activité promotionnelle. Cette visite permet aux journalistes et aux acheteurs potentiels de prendre connaissance du caractère de la destination et de ses services. Elle fournit unemasse d'informations techniques. Qui plus est, elle crée des liens.

\section{Le positionnement}

Ces démarches de promotion s'appuient sur des outils de qualité, traduits en anglais et même en allemand. Brochures de positionnement, vidéo et manuel de commercialisation véhiculent une thêmatique nature/culture. Ils mettent l'accent sur deséléments demessages reliés à la mer, au littoral, à la pêcche, à la montagne, ou à la faune. La thématique est exprimée par le slogan Bas-Saint-Laurent/Gaspésie: mille kilometres de littoral et par le visuel photographique d'un paysage de montagnes sillonné par une route de bord de mer. Ce positionnement est également utilisé pour les placements-médias.

\section{Les résultats}

Pour l'année 1992, une enquête a démontré que la nouvelle clientèle hors-Québec rapportait 1,2 million $\$$ de retombées directes à l'industrie régionale. De plus, une quinzaine de publications, d'articles de journaux, de magazines ou de guides touristiques ont rapporté près de 3 millions $S$ en valeur éditoriale. En 1993, les résultats s'averrent encore plus probants avec un accroissement significatif de la dientèle française. Selon le Rapport Corbeil (février 1994), ce segment compte désormais pour $53,3 \%$ du total des visiteurs internationaux du territoire, comparativement à 19,6\% pour le marché des États-Unis. En terme d'importance pour le Bas-Saint-Laurentet la Gaspésie, le marché français se classe donc au deuxième rang, derriêre le marché québécois. La performance de notre destination sur ce marché d'outre-mer est attribuable en grande partie à la stratégie d'intégration de Tourisme Bas-SaintLaurent/Gaspésie au réseau de distribution.

\section{Gagner la confiance du réseau}

Les associations touristiques, les bureaux de congrès et d'autres organismes de positionnement peuvent, à certains égards, représenter unemenace pour les voyagistes réceptifs du Québec. C'est le cas lorsqu'ils favorisent la vente directeentreles acheteurs européens et les vendeurs de leur région. L'Association touristique joue un rôle de positionnement et ses relations d'affaires avec les acheteurs se résument, en général, à un support promotionnel et à de l'assistance technique ou financière. En respectant ces règles tacites de l'industrie, il aura fallu quelques années à Tourisme BasSaint-Laurent/Gaspésie pour établir une relation de confiance avec ses nouveaux partenaires. Aujourd'hui, presque tous les voyagistes réceptifs du Québecet plusieurs de l'Ontario et des Maritimes, font appel aux services de l'organisme, à ses outils promotionnels, à ses conseils dans la planification des itinéraires.

Le succès d'une importante tournée de familiarisation, à l'été 1993, illustre bien cette relation de confiance. Une quinzaine de voyagistes européens ont découvert, avec la colla boration de Via Rail, un circuit par train et par autobus à partir de Montréal. Des réceptifs du Québec ont accepté de confier les noms de quelques clients potentiels à Tourisme Bas-Saint-Laurent/ Gaspésie qui a pris en charge l'organisation complète de la tournée. Dans chaque invitation, on pouvait lire le nom du voyagisteréceptif concerné. Lejuste retour des choses.

\section{L'avenir}

Tourisme Bas-Saint-Laurent/Gaspésie compte poursuivre ses actions promotionnelles sur une base permanente. Afin d'assurer son autonomie d'ici cinq ans, le milieu devra contribuer encore davantage au financement. Une nouvelle campagne de recrutement se déroulera d'ailleurs en 1994.

En développant un tel organisme de promotion internationale, ces régions touristiques éloignées des centres urbains ont su se positionner sur des marchés tels que la France, les États-Unis, l'Angleterre et l'Allemagne. La promotion des régions comme les nôtres passe normalement par lesreprésentantsdu ministèredu Tourisme ou de Tourisme Canada, mandatés pour vendre l'ensemble des produits de toutes les destinations. A toute fin pratique, seuls les offices de tourisme des deux grandes villes du Québec se commercialisent sur une base autonome et permanente.

La force de vente du Québec à l'étranger doit s'appuyer sur la richesse du territoire, sur la diversité de ses produits. Dans ce tableau, les régions occupent une place aussi importante que les grandes villes. Cependant, chacun ne peut prétendre réussir individuellement à se tailler une place dans un marché aussi vaste. Même la force apparente du produit touristique d'une région donnéen'est pas garanted'un éventuel succès. Les régions doivent travailler ensemble pour améliorer leur offre et surtout pour assurer une continuité dans leurs activités promotionnelles. $\mathrm{La}$ commercialisation internationale est un processus lent qui demande des efforts soutenus. Si la recette est bien appliquée, elle peut rapporter gros, pendant longtemps. Pour Tourisme Bas-Saint-Laurent/ Gaspésie, la concertation füt l'ingrédient de base. A bon entendeur, salut! " 